Michael J. Dueker is a senior economist, Federal Reserve Bank of St. Louis, and Andreas M. Fischer is economic adviser, Swiss National Bank, Zürich, Switzerland. The authors are responsible for this article's content, which does not represent official positions of the Federal Reserve Bank of St. Louis, the Federal Reserve System, or the Swiss National Bank.

\section{Are Federal Funds Rate Changes Consistent with Price Stability? Results from an Indicator Model}

\section{Michael J. Dueker and Andreas M. Fischer}

\footnotetext{
or U.S. monetary policy, 1994 was an eventful year. Despite little change in measured price inflation, expectations of inflation began increasing in late 1993, as interest rates on 10-year government bonds climbed more than 150 basis points between October 1993 and April 1994. Against this backdrop, the Federal Reserve raised the target federal funds rate in February 1994, the first of seven increases in a span of 12 months. Before this, the Fed had held the target funds rate steady at 3 percent since September 1992. Most market watchers interpreted the increases in the target funds rate between February 1994 and February 1995 as monetary tightening. Because there is no clear link between an inflation target and adjustments of the Federal Reserve's funds rate target, however, interpreting funds rate changes is often difficult.

The purpose of this article is to explain changes in the federal funds rate as the outcome of an implicit policy of inflation targeting. We advance the view that the increases in the federal funds rate in 1994 were designed to target a
}

low and relatively stable inflation rate. The empirical strategy is to extract from funds rate changes an estimated inflation target, which serves as an indicator of the stance of monetary policy. With this indicator, it is possible to analyze whether the recent string of seven increases in the federal funds rate was consistent with a constant inflation target. In other words, our indicator model suggests that the fundamental stance of monetary policy can remain unchanged, even when the funds rate is changing, provided that the funds rate changes are consistent with a constant target inflation rate. By contrast, the conventional view holds that interest-rate hikes necessarily connote a change in the stance of monetary policy.

In the next section we describe the interest-rate feedback mechanism (or policy rule) used to describe U.S. monetary policy and the meaning of its parameters. We also contrast our 1994 indicator model with Taylor's (1993) rule, although both specify current adjustments to interest-rate instruments believed to be consistent with achieving a long-run inflation target. Our empirical model, like Evans and Wachtel (1993), identifies changes between inflation regimes. The variable that switches in our model, however, is "intended" or target inflation, as opposed to realized inflation.

The subsequent section presents estimates of implicit inflation targets in the past 25 years and dates when the inflation target appeared to shift.

In the final section we offer some answers to these three questions:

- How close to price stability has the implicit inflation target been in the past?

- How close to price stability is the implicit inflation target now?

- How well does a model of inflation targeting describe actual monetary policy decisions? 


\section{IMPLICIT INFLATION TARGETS AND FEEDBACK MECHANISMS}

Because the United States has no formal inflation targets, the implicit inflation target needs to be estimated. Our indicator model assumes an inflationtargeting regime, where policymakers look one year ahead and aim to close the gap between the current inflation rate and a target rate. Such a one-year-ahead framework closely resembles the practice in countries that have announced explicit annual or multi-year inflation targets, such as the United Kingdom, Canada, Sweden, Finland, and New Zealand. Leiderman and Svensson (1995) provide an overview of policies in countries with formal or semiformal inflation targets. The Reserve Bank of N ew Zealand, for example, announced a "step function" of decreasing annual inflation targets as a path toward a long-run target of 0 to 2 percent annual inflation.

Dueker and Fischer (1994) argue that inflation indicator models provide useful information regarding implicit inflation objectives embedded in past and present policy actions. The goal of the indicator model is to provide a guide for monetary policy discussion by illustrating whether currently contemplated policy actions are consistent with the current implicit target or baseline rate of inflation. We estimate the implicit inflation target as a time-varying parameter in an interest-rate feedback mechanism. Feedback comes from the price level, which could be targeted in levels; the growth rate (the inflation rate); or an intermediate policy, a combination of the two, with a levels target that gradually accommodates drift in the target path.

\section{Targeting Inflation Using a Monetary Instrument}

W hen targeting inflation using an interest-rate instrument, the key question is, By how much should the funds rate change so that it is expected, but not certain, that inflation will adjust as desired in the coming year? This question is analogous to asking, By how much does the money supply have to grow to hit a nominal gross domestic product (GDP) growth target? With the latter, it is well-known from the equation of exchange that the predicted income velocity of money is an important link between desired nominal income growth and money growth. Nevertheless, it is instructive to review why velocity forecasts are so useful for targeting nominal GDP with a monetary instrument.

In this example, if $y$ is the log of nominal GDP,

$$
\widehat{\Delta y}
$$

is desired nominal GDP growth, $v=(y-m)$ is the log of velocity, $\Delta(y-m)_{t t-1}$ is a forecast of velocity growth at time t conditional on information available through time t- 1 and $\Delta \mathrm{m}$ is money growth, then the targeting procedure described above prescribes the following rate of money growth:

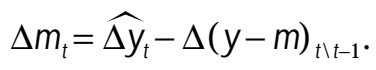

Note that the accuracy of the forecasted value of $(y-m)$ ought to be somewhat robust to alternative money growth rates, because we have reason to believe that higher money growth will be offset by higher nominal GDP growth, leaving $(y-m)$ little changed. If money growth were set according to a forecast of $(y+m)$, on the other hand, such that

$$
\Delta \mathrm{m}_{\mathrm{t}}=-\widehat{\mathrm{y}}_{\mathrm{t}}+\Delta(\mathrm{y}+\mathrm{m})_{\mathrm{t} \mid \mathrm{t}-1},
$$

there would be little reason to believe that the forecasted value of $(y+m)$ would be accurate for a range of values for $\Delta \mathrm{m}$. If the growth rate for $m$ were to increase, no economic model would suggest that growth in nominal GDP would decrease to maintain a nearly constant value of $(y+m)$. Therefore, because we believe a positive relationship exists between money growth and nominal GDP growth, $(y-m)$ is forecasted and the appropriate targeting procedure is given in equation 1 .

\section{Targeting Inflation Using An Interest-Rate Instrument}

A similar issue arises in targeting inflation with an interest-rate instrument. 
If $\mathrm{R}$ is the nominal interest-rate policy instrument (the federal funds rate) and $\pi$ is the inflation rate as measured by the consumer price index, then one possibility is to forecast changes in the real rate of interest, $\Delta(R-\pi)$. Wicksellian theory, however, suggests that decreases in interest rates do not cause offsetting decreases in the inflation rate in the short run. Wicksell (1936) argues that monetary policy can effect short-run changes in the real interest rate charged on bank loans relative to the marginal real return on physical capital. ${ }^{1}$ Furthermore, tight monetary policies that raise market interest rates (relative to the marginal efficiency of investment in new capital), lead to a shortfall in investment (relative to savings) and to disinflation.

Conversely, an easy monetary policy that pushes market interest rates temporarily below the marginal efficiency of investment creates an inflationary surge in investment and aggregate demand. Hence, our model uses a forecast of $\Delta(R+\pi)$ under the assumption that increases in interest rates initiate disinflations, so that increases in $\mathrm{R}$ can be offset by decreases in $\pi$. In this case, the accuracy of the forecast is somewhat robust to alternative values of $\Delta R$. But monetary policy can only create a temporary wedge between the real interest rate charged on bank loans and the real return to physical capital. Disinflation eventually brings about decreases in nominal interest rates, as suggested by the long-run Fisher equation $R=r+\pi$, where $r$ is the long-run equilibrium real rate of return. Carlstrom (1995) refers to this dynamic as the paradox of interest rates: Interest rates must rise in the short run in order to fall in the long run. The Wicksellian view concurs that nominal interest rates must increase to raise the real rate of interest on loans for a given level of expected inflation to generate disinflation, which eventually leads to a lowering of inflation expectations and nominal interest rates.

The specific model of inflation targeting through manipulation of the funds rate follows. If $\pi_{0 t}$ is the inflation target, then $\pi_{\mathrm{t}-1}-\pi_{0 \mathrm{t}}$ is the latest information regarding the gap between recent and target inflation.
In this case, the desired change in the inflation rate from the present to the end of the coming year is

$$
\widehat{\Delta \pi}_{\mathrm{t}}=\left(\pi_{0 \mathrm{t}}-\pi_{\mathrm{t}-1}\right) .
$$

As discussed above, our model uses forecasts of $\Delta(R+\pi)$ in modeling funds rate changes with the following inflation-targeting mechanism:

$$
\begin{gathered}
\Delta \mathrm{R}_{\mathrm{t}}=-\widehat{\Delta \pi}_{\mathrm{t}}+\Delta[\mathrm{R}+\pi]_{\mathrm{t} \mid \mathrm{t}-1} \\
\widehat{\Delta \pi}_{\mathrm{t}}=\left(\pi_{0 \mathrm{t}}-\pi_{\mathrm{t}-1}\right) .
\end{gathered}
$$

In using equation 2 as a model of funds rate changes, it is necessary to estimate $\pi_{0}$. We must also supply time-series forecasts for $\Delta[R+\pi]_{t \mid t-1}$ as an input to equation 2. Our approach is to estimate a time-varying coefficient model, as in Dueker (1993), using the Kalman filter to generate the forecasts under the assumption that the regression coefficients follow a random walk:

$$
\begin{aligned}
\Delta(\mathrm{R}+\pi)_{\mathrm{t} \mid \mathrm{t}-1}= & \beta_{\mathrm{ot}}+\beta_{1 \mathrm{t}} \Delta \pi_{\mathrm{t}-1}+\beta_{2 \mathrm{t}} \Delta \mathrm{R}_{\mathrm{t}-1} \\
& +\beta_{3 \mathrm{t}}\left(\mathrm{TBond}_{\mathrm{t}-1} / \mathrm{TBC}_{\mathrm{t}-1}\right),
\end{aligned}
$$

where inflation is the percentage change in the consumer price index, the TBond is the 10-year government bond rate, and TB3 is the 3-month Treasury bill rate. [ $F_{t \mid t-1}$ is defined to be the forecast error variance of the term $\Delta(R+\pi)_{t}-\Delta(R+\pi)_{t \mid t-1 .]}$ The empirical model also includes an error term, e, for deviations between actual funds rate changes and the changes implied by the inflation-targeting procedure, where $e_{t}$ is independently distributed with mean zero and a parameter $\sigma_{\mathrm{t}}^{2}$, which is proportional to the variance

$$
\Delta \mathrm{R}_{\mathrm{t}}=-\widehat{\Delta \pi}_{\mathrm{t}}+\Delta[\mathrm{R}+\pi]_{\mathrm{t} \mid \mathrm{t}-1}+\mathrm{e}_{\mathrm{t}} .
$$

The indicator model of equation 4 draws on the concept of nominal feedback rules, introduced by McCallum (1987, 1988). It uses a feedback mechanism to adjust the policy instrument (the funds rate) in response to recent developments in inflation. Our model differs from the work of McCallum $(1987,1988)$ and Judd and Motley (1993) by using an interest-

\footnotetext{
${ }^{1}$ For more details on the Wicksellian framework, see Wicksell (1936) and Humphrey (1986).
} 
rate feedback mechanism as a model of past and current policy, rather than as a tool to simulate hypothetical policies. In our model, the target rate of inflation is not a normative concept, but a time-varying parameter to be estimated. The model fulfills a positive function by ascribing implicit objectives to recent and past policies.

Taylor's rule (1993) also describes past interest-rate policy in terms of a long-run inflation objective, but his rule does not aim at a particular inflation target for the coming year. In the Taylor rule, the interest-rate instrument remains above or below its long-run level for as long as a gap persists between recent and long-run target inflation, but there is no timetable for achieving the target rate. ${ }^{2}$ Our framework, in contrast, centers on a one-year timetable for achieving a desired inflation rate.

\section{Time-Varying Estimates of The Inflation Target}

Because the implicit inflation target of the Federal Reserve has likely changed during the past 25 years, we allow $\pi_{0 t}$ to vary through time between a high and a low state according to an unobservable Markov process. Evans and Wachtel (1993) also model time-varying inflation regimes with Markov processes. A two-state characterization is not as restrictive as it might first appear, because the states are unobserved so that probabilistic inferences of the inflation target lie anywhere in the band between the low and high state. The estimation problem includes uncovering

2 Taylor's rule also specifies a long-run level for the nominal interest-rate instrument, whereas our model does not. Our empirical model is intended to be a behavioral equation only for the monetary authority and not the general equilibrium economy. The monetary authority need not attempt to impose prior beliefs about the long-run steady-state level of nominal interest rates in order to target inflation period by period. estimates of the probabilities of being in high- and low-inflation target states across time. The inferred value of the implicit inflation target will be the probabilityweighted sum of the high- and low-inflation targets. Because the states are allowed to be serially correlated, this probabilityweighted sum will show persistence. In this way, the model-implied target or baseline rate of inflation can adjust relatively smoothly between the high and low extremes so as to converge gradually on the target rate of a long-run disinflation like that undertaken in New Zealand.
Depending on the value of an unobserved state variable, $S 1, \pi_{0 \mathrm{t}}$ takes on either a high or a low value, both of which are parameters that must be estimated: $\pi_{0}(S 1=0)$ and $\pi_{0}(S 1=1)$. Similarly, another unobserved binary state variable, S2, governs the size of the variance: $\sigma_{\mathrm{t}}^{2}=$ $\sigma^{2}(\mathrm{~S} 2=0)$ or $\sigma^{2}(\mathrm{~S} 2=1)$. Subject to these Markov-switching state variables and an error term, equation 4 becomes

(5) $\Delta \mathrm{R}_{\mathrm{t}}=\left[\pi_{\mathrm{t}-1}-\pi_{0 \mathrm{t}}(\mathrm{S} 1)\right]+\Delta[\mathrm{R}+\pi]_{\mathrm{tt}-1}+\mathrm{e}_{\mathrm{t}}$,

where: $\mathrm{e}_{\mathrm{t}} \sim$ student- $\mathrm{t}\left(\right.$ mean $\left.=0, \mathrm{n}, \sigma_{\mathrm{t}}(\mathrm{S} 2)\right)$

Variance $(e)=\sigma^{2}(\mathrm{~S} 2) \mathrm{n} /(\mathrm{n}-2)$ $\mathrm{S} 1 \in\{0,1\} \quad \mathrm{S} 2 \in\{0,1\}$

To allow for the possibility that interestrate changes have fatter-tailed distributions than the normal distribution, we allow e to have a student- $t$ distribution with $n$ degrees of freedom.

For reasons of tractability and clarity, the two Markov processes are assumed to undergo transitions between their states independently of one another. The independence assumption precludes prior restrictions that, for example, would presuppose that inflation targeting is less disciplined on average in the high-inflation target state than in the low-inflation target state. In this case, the transition probabilities can be summarized as

(6) $\operatorname{Prob} .\left(S 1_{\mathrm{t}}=0 \mid S 1_{\mathrm{t}-1}=0\right)=\mathrm{p}_{1}$

Prob. $\left(S 1_{\mathrm{t}}=1 \mid \mathrm{S} 1_{\mathrm{t}-1}=1\right)=\mathrm{q}_{1}$

Prob. $\left(S 2_{\mathrm{t}}=0 \mid \mathrm{S} \mathrm{t}_{\mathrm{t}-1}=0\right)=\mathrm{p}_{2}$

Prob. $\left(S 2_{\mathrm{t}}=1 \mid S 2_{\mathrm{t}-1}=1\right)=\mathrm{q}_{2}$.

Note that without the independence assumption for S1 and S2, we would have to estimate 12 transition probabilities instead of 4.

\section{ESTIMATION RESULTS FOR U.S. DATA 1971-1995}

Table 1 presents the estimates of equation 5 using quarterly data from 1971:2 to 1995:3. The previous section and Dueker (1993) discuss how the forecasts were derived. The estimates for the band width of the implicit inflation target are $\pi_{0}(\mathrm{~S} 1=$ $0)=6.33$ and $\pi_{0}(S 1=1)=3.22$, with an 


\section{Table 1}

\section{Inflation Indicator Model of Funds Rate}

\begin{tabular}{l|c} 
Parameter & Estimate \\
\hline$\pi_{0}(S 1=0)$ & 6.33 \\
& $(.54)$ \\
$\pi_{0}(S 1=1)$ & 3.22 \\
& $(.361)$ \\
$\sigma^{2}(S 2=0)$ & .188 \\
& $(.044)$ \\
$\sigma^{2}(S 2=1)$ & 6.62 \\
& $(1.87)$ \\
$p_{1}$ & .942 \\
& $(.049)$ \\
$q_{1}$ & .951 \\
& $(.040)$ \\
$p_{2}$ & .937 \\
& $(.036)$ \\
$q_{2}$ & .884 \\
$1 / n$ & $(.072)$ \\
Log Likelihood & $1 E-05$ \\
Note: Standard errors are in parentheses.
\end{tabular}

unconditional probability of $\mathrm{S} 1=1$ equal to 0.54 and an unconditional value of the inflation target equal to 4.65 (arrived at through $0.46 \times 6.33+0.54 \times 3.22$ ) .

Table 1 also reveals that the variance shifts dramatically when S2 changes.

Figure 1 shows the model-implied inflation target, where the inferred target is equal to the probability-weighted sum of the high and low targets. The estimated inflation target (blue line) is plotted with a one-year moving average of actual inflation (black line). Actual inflation generally remains within the band defined by the two inflation target parameters except for two periods surrounding the twin oil shocks of the 1970s. The estimated model suggests that, since the disinflation of the early 1980s, the implicit inflation target has generally remained below 4 percent, with a notable exception being 1989-1991. A nother interesting finding is that Table 1's sample-wide estimate of the low-inflation state $\pi_{0}(S 1=1)=3.22$ is consistently higher than the actual inflation rate after 1992.

\section{Figure 1}

Implicit U.S. Inflation Target

Percent

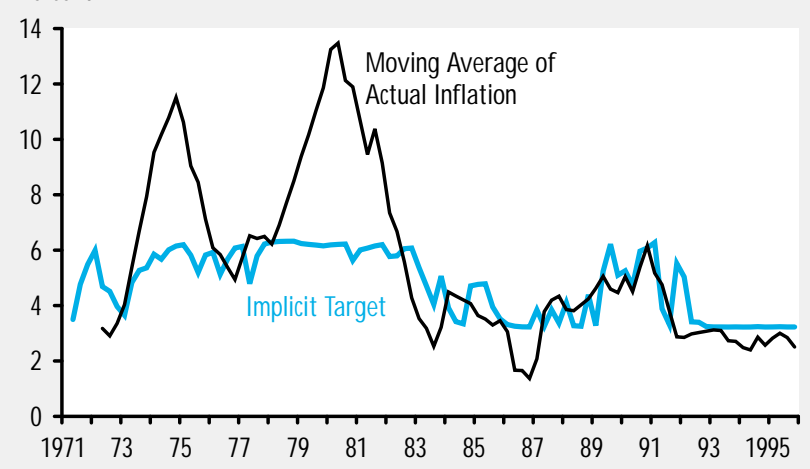

\section{Figure 2}

\section{Quarterly Short-Term Funds Rate Changes}

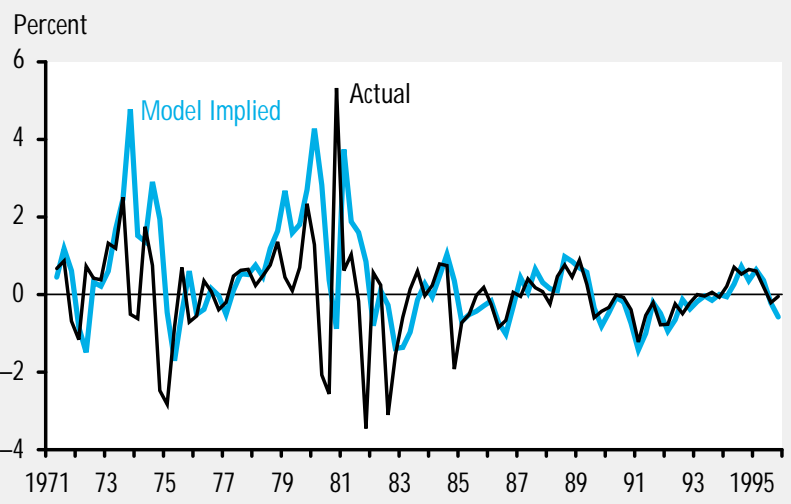

Before addressing this issue, we need to consider the model's fit. 3

To see how well the inflation-targeting model explains funds rate changes during the past 25 years, Figure 2 plots actual versus model-implied changes in the federal funds rate. The indicator model tracks the federal funds rate changes closely except for 1974-1975 and 1980-1981. The estimates of Table 1's variance parameters, $\sigma^{2}(\mathrm{~S} 2=0)$ and $\sigma^{2}(\mathrm{~S} 2=1)$, show that the standard deviation of the model's error increases by more than a factor of five in the high-volatility state where $\mathrm{S} 2=1$. In general, funds rate changes appear more consistent with a policy of inflation targeting in the second half of the sample than in the first. Even at its worst, the

\footnotetext{
${ }^{3}$ A richer version of the model with feedback from the price level gave almost identical results as those in Table 1, because the price-level feedback coefficients were essentially zero. Policy did not appear to respond to past inflation surprises by attempting to restore a price-level target.
} 
Figure 3

\section{Probability of High-Variance Deviations From Inflation Targeting and Forecast Error Variance*}

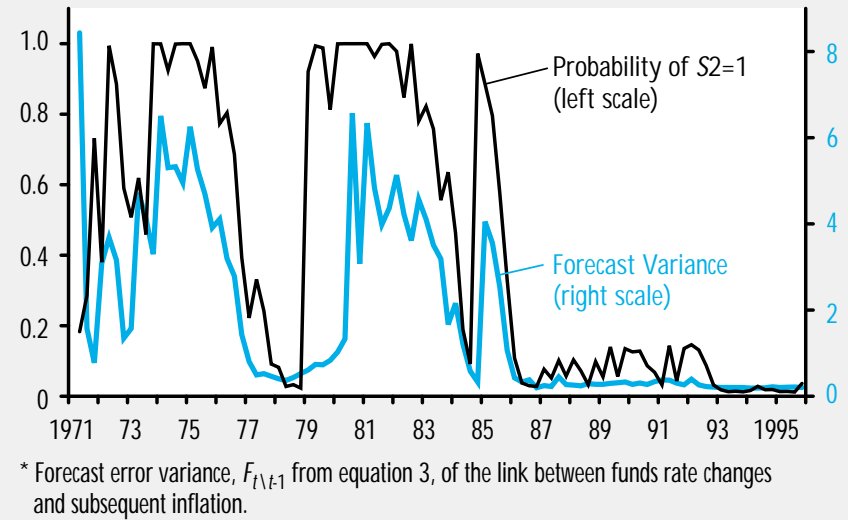

\section{Figure 4}

\section{Funds Rate Changes with Implied Changes for Alternative Inflation Targets}

\section{Percent}

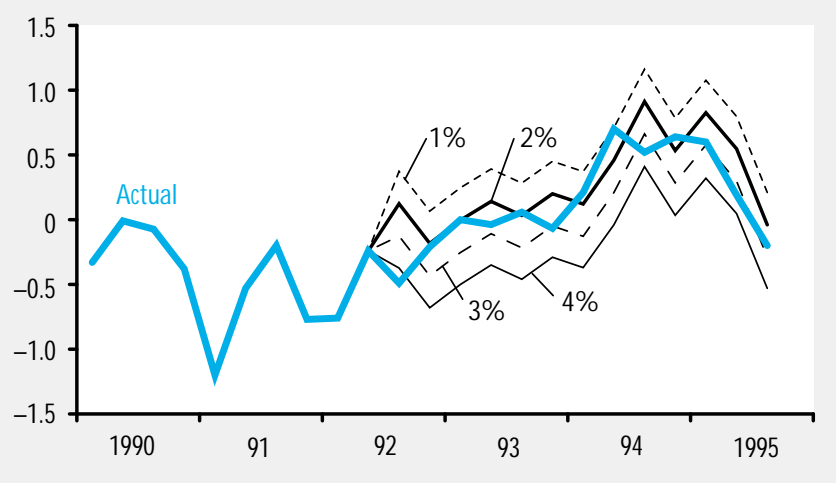

prescriptions of the inflation-targeting procedure would not have produced much greater interest-rate volatility than that actually observed. However, aggressive interest-rate increases would have begun much earlier in the late 1970s even if inflation had been targeted at 6.33 percent.

We should also look at the magnitude of the deviations from the implicit inflationtargeting specification in relation to the degree of uncertainty regarding the link between funds rate changes and subsequent inflation. Figure 3 takes the time-varying variance $\sigma^{2}$ as a measure of the magnitude of the deviations of funds rate changes from the inflation-targeting specification and compares it with the time-varying forecast error variance of $\Delta[R+\pi], F_{t \mid t-1}$. The strong positive correlation between the two variances leads to questions of causality. One possible explanation is that the uncertainty about the relationship between interest rates and inflation is extrinsic. The Fed therefore chooses to follow an inflation-targeting policy more closely when the link between policy actions and inflation outcomes is relatively clear. An alternative view is that a policy of inflation targeting helps pin down the relationship between inflation and the funds rate, thereby lowering the forecast error variance. An attempt to sort out the direction of causality is beyond the scope of this article. Figure 3 is intended merely to highlight an interesting correlation between the two variances.

With regard to how close the policyimplied baseline rate inflation is to and has been to price stability, our results suggest that significant progress has been made since the 1970s and 1980s. The baseline rate of inflation has been firmly anchored in the low-inflation state since 1992. The baseline inflation rate from the mid-1980s to the early 1990s, in contrast, was less firmly placed in the low-inflation state. From Figure 1, it appears that the estimated parameter $\pi_{0}(\mathrm{~S} 1=1)=3.22$ is perhaps too high to describe the inflation target in the mid1990s. To investigate this conjecture, we imposed alternative values of $\pi_{0}$ to the post-1991 period to see which best describes the actual changes in the funds rate. Figure 4 compares results for values of $\pi_{0}$ ranging from 1 percent to 4 percent. The actual changes in the funds rate have generally been between the changes suggested by the 2 percent and 3 percent inflation targets. The ease in September 1992, however, was more consistent with the 4 percent target.

Although some observers believed that the Fed had maintained a funds rate target of 3 percent for too long during 1993, Figure 4 shows that the actual changes in the funds rate remained between bounds implied by 2 percent and 3 percent inflation targets throughout 1993. The initial increases in the funds rate in early 1994 were consistent with the adoption of a 
target between 1 percent and 2 percent. The actual funds rate changes, however, soon returned to the range consistent with an inflation target between 2 percent and 3 percent. Finally, the 25 basis point cut in the target funds rate in July 1995 was consistent with the overall thrust of the funds rate changes during the previous three years- more consistent with an implicit inflation target between 2 percent and 3 percent than with the sample-wide parameter estimate $\pi_{0}(S 1=1)=3.22$. The experiment cannot be regarded as a complete counterfactual account of what would have happened if the implicit inflation target had really been, say 2 percent, throughout the post-1991 period, because such counterfactual accounts require simulations of a fully specified model of the economy that characterizes all relevant interaction between inflation and monetary policy. Our experiment shows what would have happened, for example, if the Fed had each period adopted a 2 percent inflation target, taking the past as given. Nevertheless our experiment does help indicate whether a given change in the funds rate was more consistent with a 2 percent inflation target vs. a 4 percent inflation target.

\section{MEASURING PROGRESS TOWARD PRICE STABILITY}

We have presented an inflation targeting model of U.S. monetary policy to examine how closely inflation targeting describes past policy and, if so, how the implicit inflation targets appeared to vary across time. The inflation target inferred from the model increases to more than 6 percent by the mid-1970s and begins to decline in 1983. By 1984, the Fed had engineered a decrease in the trend rate of inflation to less than 3.5 percent. The model detects some backsliding that had occurred by the late 1980s, when the trend rate briefly rose again. The early 1990s, however, witnessed a disinflation that brought the baseline rate of inflation to about 3 percent. Our model finds that the series of seven increases in the funds rate within a year (from early 1994 to early
1995) corresponds with a policy of holding the implicit inflation target relatively steady at a rate between 2 percent and 3 percent. $\mathrm{N}$ evertheless, a gap remains between this level of inflation and what might be called "price stability."

Our results also uncover a strong positive correlation between the forecast error variance in the uncertain relationship between funds rate changes and subsequent inflation and the extent to which inflation targeting describes the actual funds rate changes. One explanation for this correlation is that the Fed has targeted inflation more stringently during periods when policymakers could be relatively confident in using the funds rate as an instrument to target inflation. Alternatively, an inflation-targeting regime might engender a tighter relationship between the funds rate and inflation.

\section{REFERENCES}

Carlstrom, Charles. "A Monetary Policy Paradox," Federal Reserve Bank of Cleveland Economic Commentary (August 15, 1995).

Dueker, Michael J. "Indicators of Monetary Policy: The View from Implicit Feedback Rules," this Review (September/ October 1993), pp. 23-39. and Andreas M. Fischer. "Inflation Targeting in a Small Open Economy: Empirical Results for Switzerland," Journal of Monetary Economics (forthcoming).

Evans, Martin, and Paul Wachtel. "Inflation Regimes and the Sources of Inflation Uncertainty," Journal of Money, Credit and Banking (August 1993, part 2), pp. 475-511.

Humphrey, Thomas M. Essays on Inflation, 5 th ed. Federal Reserve Bank of Richmond, 1986.

Judd, John P., and Brian Motley. "Using a Nominal GDP Rule to Guide Discretionary Monetary Policy," Federal Reserve Bank of San Francisco Economic Review (No. 3, 1993), pp. 3-11.

Leiderman, Leonardo, and Lars E. 0. Svensson. Inflation Targets. London: Centre for Economic Policy Research (1995).

McCallum, Bennett T. "The Case for Rules in the Conduct of Monetary Policy: A Concrete Example," Federal Reserve Bank of Richmond Economic Review (September/ October 1987), pp. 10-18. . "Robustness Properties of a Rule for Monetary Policy," Carnegie-Rochester Conference Series on Public Policy (Vol. 29, 1988), pp. 173-204.

Taylor, John B. "Discretion versus Policy Rules in Practice," CamegieRochester Conference Series on Public Policy (Vol. 39, 1993), pp. 195-214.

Wicksell, Knut. Interest and Prices. R. F. Kahn, translator, with an introduction by Bertil Ohlin. London: Macmillan (1936). 